\title{
MIG brazing of 304L type stainless steel using CuSi3 and CuSi3MnAl brazing wire
}

\author{
P. Sejč*, R. Kubíček \\ Slovak University of Technology in Bratislava, Faculty of Mechanical Engineering, \\ Pionierska 15, 83102 Bratislava, Slovak Republic
}

Received 7 May 2014, received in revised form 11 February 2015, accepted 27 February 2015

\begin{abstract}
Within the technical practice of austenitic stainless steel welding, mostly fusion arc welding processes, or less frequently, high energy density fusion processes are commonly being used. When applying fusion welding process in terms of stainless steel weldability, fabricators face different technological and metallurgical limitations, which are mostly connected to the melting and following crystallization of the weld metal, or excessive heat input resulting into deformation of a weldment. As the MIG brazing process enables a formation of the weld without melting of base material and is also providing relatively low level of heat input to the material, the above-mentioned advantages are subject to research within submitted paper.

The paper is focused on the analysis of MIG brazing application possibilities of joining 304L stainless steel using CuSi3 and CuSi3MnAl types of brazing wire.
\end{abstract}

K e y wo r d s: MIG brazing, austenitic stainless steel 304L, heat input, brazing wire CuSi3, brazing wire $\mathrm{CuSi} 3 \mathrm{MnAl}$

\section{Introduction}

For some years, MIG brazing (GMAB) has been one of the commonly used technologies applied to joining thin zinc-coated plates $[1-5]$. Today, this technology is most widely used within joining automotive structural components, where in many cases it replaced technology of MAG welding process (GMAW). Advantages of GMAB application are: less heat input to a brazed joint compared to GMAW process (the melting temperature of filler materials is between 950 to $1080^{\circ} \mathrm{C}$ ), less heat induced stresses and deformations (an advantage mostly when joining thin plates), and a resistance of the joint against an atmospheric corrosion. These advantages are leading to the analysis of the possibilities of GMAB application also for joining heterogenic joints (e.g. for steel zinc-coated plates to aluminium [6]) and for joining austenitic stainless steel.

The main factor directly affecting the brazeability of austenitic stainless steel is a proper selection of brazing filler material. Austenitic stainless steels are characterized by a relatively high level of the thermal expansion and low thermal conductivity. The combination of these properties handles deformations, what creates a main technological brazing issue. When designing a joint to be used, the temperature condition such as the thermal cycle of brazing and type of cooling have to be taken into account. For the application with the requirement on high corrosion resistance, it is important to limit the formation of carbides of chrome due to susceptibility to intergranular corrosion (IGC) [11]. The susceptibility on precipitation of carbides depends on the temperature and heat-up rates, the content of carbon, grain size, the ability to plastic deformation and content of stabilizing elements $(\mathrm{Ti}, \mathrm{Nb})$. Considering critical temperature range 425 to $815^{\circ} \mathrm{C}$ of $\mathrm{M}_{23} \mathrm{C}_{6}$ precipitation, the thermal cycle of GMAB process compared to GMAW or GTAW, provides a shorter time of exposure.

The advantage of GMAB is also high productivity and low investment costs. With an exception of the necessity of replacing the steel wire filler material for $\mathrm{Cu} / \mathrm{Al}$ brazing wire, the same GMAW equipment can be used. The process can be employed in semiautomatic or automatic form, which allows reaching

*Corresponding author: e-mail address: pavol.sejc@stuba.sk 
Table 1. Chemical composition of ASTM SA240 TP304L [12]

\begin{tabular}{lcccccccc}
\hline \multicolumn{1}{l}{ Material } & \multicolumn{7}{c}{ Chemical composition (\%) } \\
\hline \multirow{2}{*}{ ASTM SA240 TP 304L } & $\mathrm{C}$ & $\mathrm{Si}$ & $\mathrm{Mn}$ & $\mathrm{Ni}$ & $\mathrm{Cr}$ & $\mathrm{N}$ & $\mathrm{S}$ & $\mathrm{P}$ \\
& 0.027 & 0.39 & 1.35 & 8.02 & 18.27 & 0.063 & 0.002 & 0.034 \\
\hline
\end{tabular}

Table 2. Mechanical properties of base and filler metals [12-14]

\begin{tabular}{lcccc}
\hline \multirow{2}{*}{ Material } & \multicolumn{3}{c}{ Mechanical properties } \\
\cline { 2 - 4 } & $R_{\mathrm{e}}(\mathrm{MPa})$ & $R_{\mathrm{m}}(\mathrm{MPa})$ & $A 5(\%)$ & HRB \\
\hline ASTM SA240 TP 304L & 295 & 648 & 53 & 87 \\
CuSi3 (OK AUTROD 19.30) & 130 & 350 & 40 & - \\
CuSi3MnAl (MECUFIL 903Al) & 360 & 540 & 40 & - \\
\hline
\end{tabular}

Table 3. Chemical composition of filler metals $[13,14]$

\begin{tabular}{|c|c|c|c|c|c|c|c|c|c|c|}
\hline \multirow{2}{*}{ Material } & \multicolumn{10}{|c|}{ Chemical composition (\%) } \\
\hline & $\mathrm{Mn}$ & $\mathrm{Si}$ & $\mathrm{Ni}$ & $\mathrm{Cu}$ & $\mathrm{Sn}$ & $\mathrm{Zn}$ & $\mathrm{Al}$ & $\mathrm{Fe}$ & $\mathrm{Pb}$ & Co \\
\hline CuSi3 (OK AUTROD 19.30) & 0.98 & 2.99 & 0.004 & Rest & 0.007 & 0.1 & 0.008 & 0.15 & 0.01 & 0.07 \\
\hline CuSi3MnAl (MECUFIL 903Al) & 1.48 & 2.67 & - & Rest & - & - & 1.41 & - & - & - \\
\hline
\end{tabular}

higher productivity compared to manually applied brazing processes.

\section{Experimental}

Submitted paper has been focused on the analysis of:

- the process of production of austenitic stainless steel joints, using GMAB technology with solid and flux-cored wires,

- mechanical properties of overlapped joints obtained by static tension testing,

- the geometry and structure of brazed joints (wetting conditions, mixture ratio between filler metal and base material, presence of surface and volumetric defects, brazing structure and diffusion zones from the side of base material and the side of filler metal).

The base material - the austenitic stainless steel of designation ASTM SA340 TP 304L in the form of a plate of $2.0 \mathrm{~mm}$ thickness was used for the production of experimental samples. Mechanical properties and chemical compositions specified based on the inspection certificate for a particular heat number used are included in Tables 1, 2.

As a filler material, following types have been selected:

1. Wire of type CuSi3 with commercial designation OK AUTROD 19.30, diameter $\varnothing=1.0 \mathrm{~mm}$ (SFA/AWS: A5.7 ERCuSi-A). Chemical composition and mechanical properties of weld metal are documented in Tables 2, 3. The wire $\mathrm{CuSi} 3$ is characterized by a relatively low melting temperature point compared to $\mathrm{CuAl}$, or $\mathrm{CuSn}$ types, which enables to process at relatively low heat input to the joint. The wire can be used under the protective atmosphere of Ar. The filler material CuSi3 currently belongs among the most commonly used filler materials within the GMAB process.

2. Flux-cored wire of $\mathrm{CuSi3MnAl}$ type with diameter $\varnothing=1.0 \mathrm{~mm}$ (DIN 1733 specification: SG-CuSi3MnAl), supplied under the commercial designation MECUFIL 903Al. The wire is characterized by the good stability of an electric arc and metal transfer with a low level of spattering. Chemical composition and mechanical properties of $\mathrm{CuSi3MnAl}$ weld metal are documented in Tables 2, 3.

Experiments have been performed in two following stages:

1. In the first stage, built-up layers of a filler material were performed at various heat input values employing the short arc transfer mode. Based on visual evaluation supported by the macroscopic examination of cross sections, the aim of this stage was to optimize brazing parameters and conditions. The stage evaluation has been focused on the following:

- influence of the filler material type on the geometry of built-up layer (width of overlay, height of overlay),

- influence of the heat input $Q$ on the depth of 


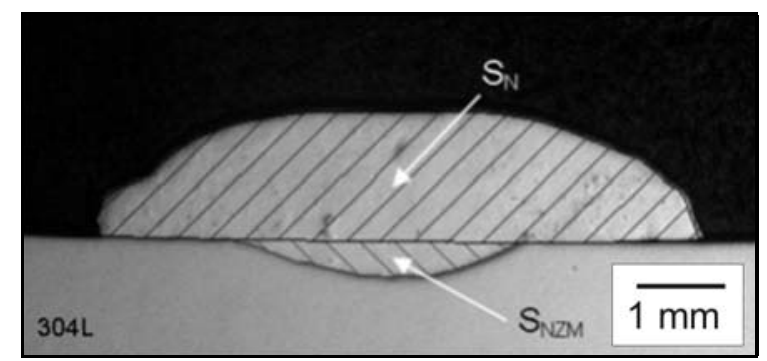

Fig. 1. Determination of mixture ratio $\Psi$.

melting penetration to the base material and mixture ratio between filler and base material, braze wetting angle $\alpha$.

2. In the second stage, overlapped sample joints were performed in the scope of optimized brazing parameters and conditions and the selected type of filler material. The sample joints were further subjected to:

- visual testing aimed at an identification of surface defects,

- static tension testing,

- structure analysis of overlapped joints, supported by semi-quantitative EDX.

For the production of experimental built-up layer samples and overlapped joint samples, plates prepared by cutting to dimensions $100 \times 300 \mathrm{~mm}^{2}$ were used. As the welding equipment, source Hobart Arc Master 501 with feeding equipment Hobart Ultrafeed $1000 \mathrm{~A}$ was employed. The universal welding positioning device designated as UZP-01(f. Formica, s.r.o.) was used for the positioning of a base material, as well as for positioning and movement of a torch. The mentioned equipment enabled to apply following brazing parameters: short arc metal transfer mode, effective value of current $I=82-98$ A, effective value of voltage $U=$ 11.3-14.3 V, torch travel speed (brazing speed) $v=$ $5.7-13.0 \mathrm{~mm} \mathrm{~s}^{-1}$, protective gas: Ar 4.6, flow rate 14 $1 \mathrm{~min}^{-1}$. The heat input $Q$ was calculated complying with standard STN EN 1011-1:

$$
Q=k \frac{U I}{v} \times 10^{-3} \quad\left(\mathrm{~kJ} \mathrm{~mm}^{-1}\right),
$$

where $U$ is brazing voltage $(\mathrm{V}), I$ is brazing current (A), $v$ is brazing speed $\left(\mathrm{mm} \mathrm{s}^{-1}\right), k$ is the coefficient of thermal efficiency of the welding process, $k$ (GMAW process $)=0.8[15]$.

Macrostructure cross sections of the braze built-up layer samples were prepared by standard metallographic procedure. The geometry of a built-up layer and depth of melting penetration to the base material were measured on the cross sections using software Image J, intended for an image analysing.

The mixture ratio was specified by an area of melted zone in the base material divided by total area of building up layer (Fig. 1), according to the formula:

$$
\Psi=\frac{S_{\mathrm{NZM}}}{S_{\mathrm{CEL}}} \times 100(\%)
$$

where $S_{\mathrm{NZM}}$ is the area of the base material melted zone, $S_{\mathrm{CEL}}$ is the total area of the building up layer, $S_{\mathrm{CEL}}=S_{\mathrm{NZM}}+S_{\mathrm{N}}$, where $S_{\mathrm{N}}$ is the area of the building up layer.

The strength of overlapped joints was evaluated by tensile testing according to standard STN ISO 6892-1. Conditions of tensile testing are as follows:

- tensile machine ZDM 10/91,

- specified force range: $20 \mathrm{kN} \pm 25 \mathrm{~N}$,

- the speed of the cross head: $10 \mathrm{~mm} \mathrm{~min}^{-1}$.

Specimens of width $s=16.95 \pm 0.05 \mathrm{~mm}$ were prepared by cutting, using cooled cutting tool.

In order of more detailed analysis of chemical and structural composition of the braze and interface layers, an electron microscope JEOL JSM 6610 equipped by the energy dispersive analyser Oxford Instruments $\mathrm{X}$-Max was employed.

\subsection{Evaluation of quality and the properties of built-up brazed layers}

Cross sections of built-up layer samples and corresponding measured values of a mixture ratio and braze wetting angle are given in Table 4.

Based on the visual testing results and measurement of geometrical properties of built-up brazed layers, following findings resulted:

1. With respect to the results of macrostructure on built-up layer cross sections performed using $\mathrm{CuSi3}$ wire (Table 4), it is clear, that a melting of the base material took place on each of the brazed samples (samples no. 11 and 13). The depth of the base material melting penetration and mixture ratio increases by elevating heat input (8.2-15.1\%). Wetting of base material can be classified as "good" $\left(\alpha=48^{\circ}-84^{\circ}\right)$. Cross sections of built-up brazed layers have shown strong differences of the shape to the axis of symmetry, what again indicates deterioration of process stability.

2. Application of flux-cored wire $\mathrm{CuSi} 3 \mathrm{MnAl}$ enabled to obtain built-up layers showing a uniform width, at various brazing speeds used (Table 4). Melting of base materials was not observed, in spite of using brazing parameters providing the maximum heat input to brazed joint. Heat input did not have any influence on the wetting angle $\left(\alpha=36^{\circ}\right.$ to $\left.45^{\circ}\right)$. Besides better wetting conditions, by an observation of built-up layer cross sections performed using the flux-cored wire, we also documented built-up layer shapes with the significantly higher level of symmetry. 
Ta ble 4. Macrostructure cross section of braze built-up layers performed by GMAB process

\begin{tabular}{|c|c|c|c|c|c|c|c|}
\hline Sample & $\begin{array}{l}\text { Cross section of } \\
\text { of braze built-up } \\
\text { layers }\end{array}$ & $\begin{array}{c}\text { Braze } \\
\text { material }\end{array}$ & $\begin{array}{l}\text { Brazing } \\
\text { speed } v \\
\left(\mathrm{~mm} \mathrm{~s}^{-1}\right)\end{array}$ & $\begin{array}{l}\text { Width/height Wetting } \\
\text { of built-up angle } \\
\text { layer } \\
(\mathrm{mm})\end{array}$ & $\begin{array}{l}\text { Depth of } \\
\text { melting } \\
\text { penetra- } \\
\text { tion }(\mathrm{mm})\end{array}$ & $\begin{array}{l}\text { Mixture } \\
\text { ratio } \\
(\%)\end{array}$ & $\begin{array}{c}\text { Heat input } \\
Q \\
\left(\times 10^{-3}\right. \\
\left.\mathrm{kJ} \mathrm{mm}^{-1}\right)\end{array}$ \\
\hline
\end{tabular}

11

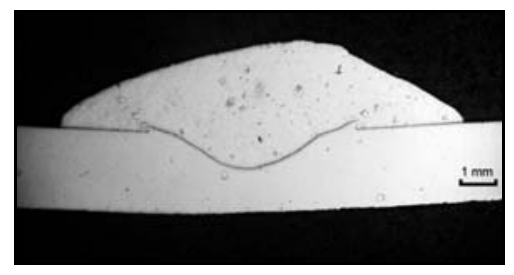

$\mathrm{CuSi} 3$

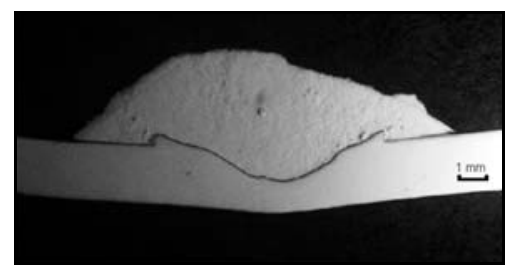

$\mathrm{CuSi} 3$

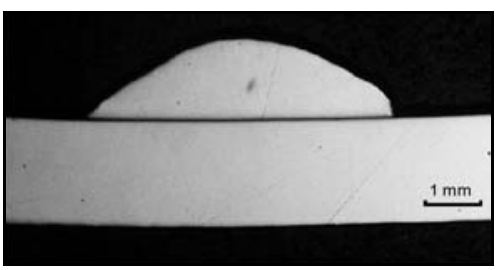

CuSi3MnAl

12.0

$5.32 / 1.59$

6.7

13.06/3.10

47.8

1.30

15.1

177.8

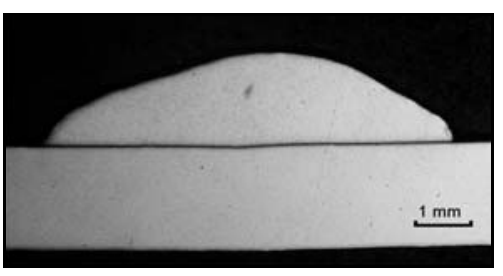

CuSi3MnAl

7.5

$7.21 / 1.83$

45.1

0

0

157.7

CuSi3MnAl

5.7

$9.42 / 2.0$

42.3

0

0

207.5

\subsection{Properties of overlapped joints}

With respect to previous results of analysed built-up layers performed by a solid wire $\mathrm{CuSi} 3$ and flux-cored wire CuSi3MnAl, a flux-cored wire was selected for the production of overlapped joints. At performing of sample built-up layers, a brazing process employing a $\mathrm{CuSi} 3 \mathrm{MnAl}$ flux-cored wire provided higher stability of an electric arc, uniform and low angle wetting of a base material and despite a maximum heat input applied, no melting of a base material took place.

Brazed joints exhibited a minimum spatter and uniform width of brazed bead (Table 4). The bead width was increasing by reducing the brazing speed caused by a higher amount of the wire building-up rate. By the application of penetration testing (PT), no surface porosity or cracking defects were indicated. Radiography testing (RT) did not detect any volumetric defects or inhomogeneity (Fig. 2).

Overlapped joints performed in the scope of brazing parameters (given in Table 5) were subjected to tensile testing. Results of tensile testing (average values of $F_{\max }$ and its standard deviation $\sigma$ ) are documented in Table 5. 
Table 5. Overlapped joints cross section and tensile testing results

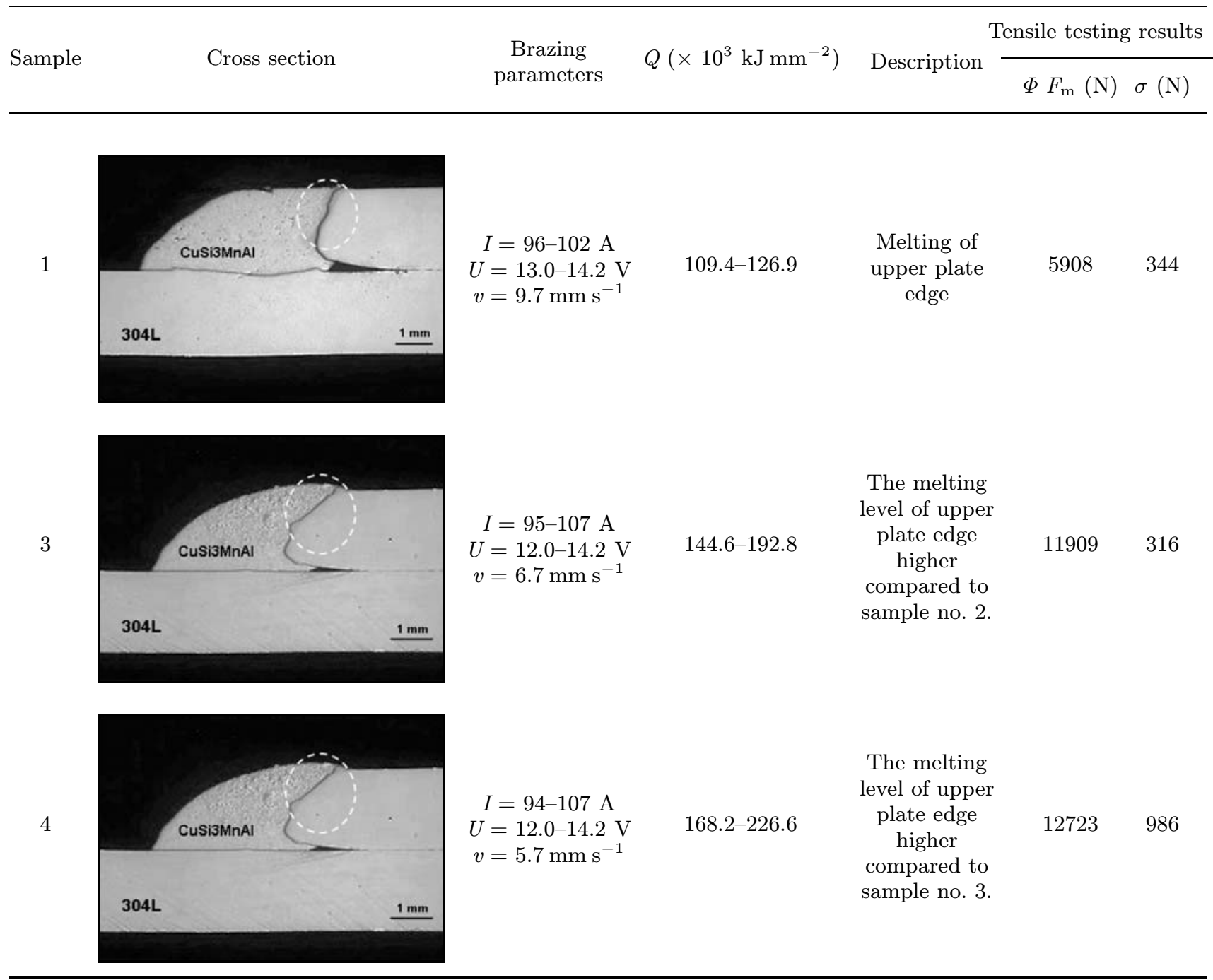

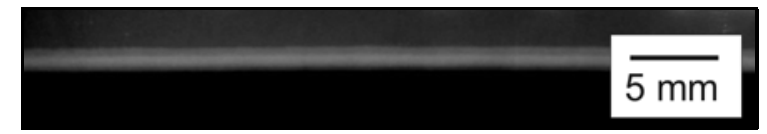

Fig. 2. Radiograph of overlapped joint (sample no. 2, Table 5). Evaluated according to EN 12517, level 1. Yxlon/Kodak MX125 used.

In the case of each specimen failure located in the braze contact area (Fig. 3), it was not possible to specify an exact gauge cross-section $S_{0}$ in the location of fracture before testing, and therefore the ultimate tensile strength $R_{\mathrm{m}}$ also could not be specified. Due to this reason, the tensile strength was evaluated based on the method of comparison between the maximum force $F_{\max }$ gained by testing of an overlapped joint and $F_{\max }$ specified based on a tensile strength of parent base material (not brazed) and constant width of the joint $(s=16.95 \pm 0.05 \mathrm{~mm})$.

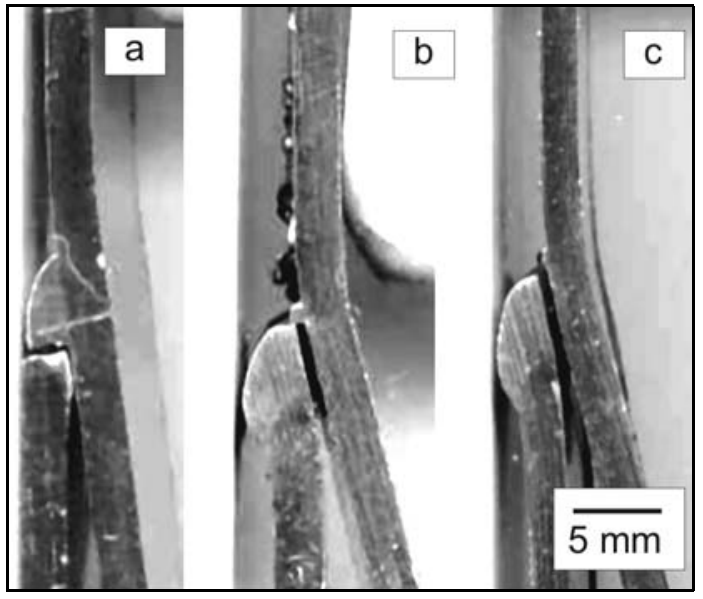

Fig. 3. Location of fracture after tensile testing: a) sample no. $1\left(v=9.7 \mathrm{~mm} \mathrm{~s}^{-1}\right)$, b) sample no. $3\left(v=6.7 \mathrm{~mm} \mathrm{~s}^{-1}\right)$, c) sample no. $4\left(v=5.7 \mathrm{~mm} \mathrm{~s}^{-1}\right)$. 


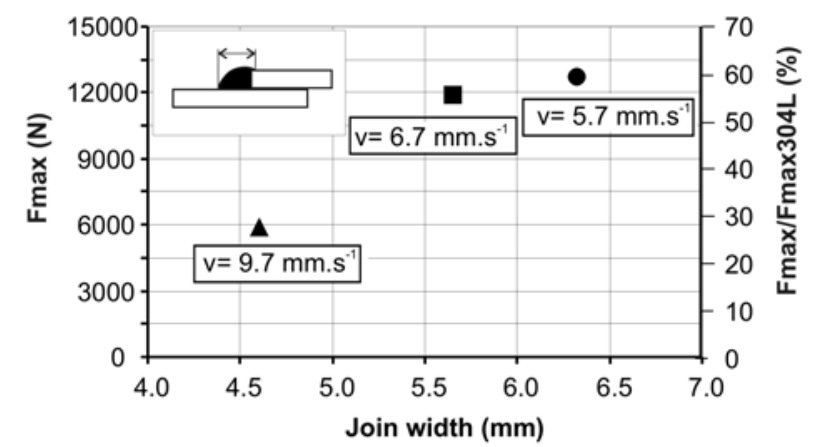

Fig. 4. Effect of the width of the braze bead on the strength of overlapped joint.

Maximum force $F_{\max }$ (load at strength) of etalon base material sample was specified from the inspection certificate 3.1 according to standard EN 10204, determined from tensile strength $R_{\max }$ of particular heat number to $F_{\max }=21969 \mathrm{~N}$. The result of strength comparison of overlapped joints with base material strength was then specified in percentual value (Fig. 4).

After the comparison of results, it can be concluded

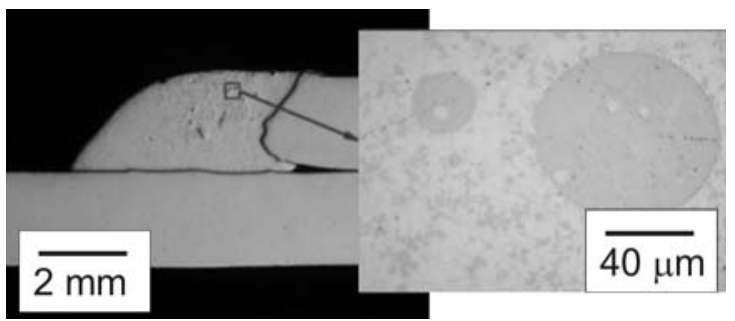

Fig. 5. Base material particles (304L) contained in $\mathrm{CuSi} 3 \mathrm{MnAl}$ braze.

that the strength of overlapped joints performed in the scope of optimized brazing parameters and wire $\mathrm{CuSi3MnAl}$ varies from 26.9 to $57.9 \%$ of base material strength. Strength increases by decreasing of brazing speed and simultaneously by increasing the bead width and braze-base material contact area. The lowest strength (26.9\% of a base material strength) was achieved at the brazing speed $v=9.7 \mathrm{~mm} \mathrm{~s}^{-1}$ (sample no. 1). By reducing brazing speed to $v=$ $6.7 \mathrm{~mm} \mathrm{~s}^{-1}$ (sample no. 3), the strength of joint increased to $52.4 \%$ of the base material strength. Further decreasing of brazing speed to $v=5.7 \mathrm{~mm} \mathrm{~s}^{-1}$ (sample no. 4) did not provide a significant elevation of

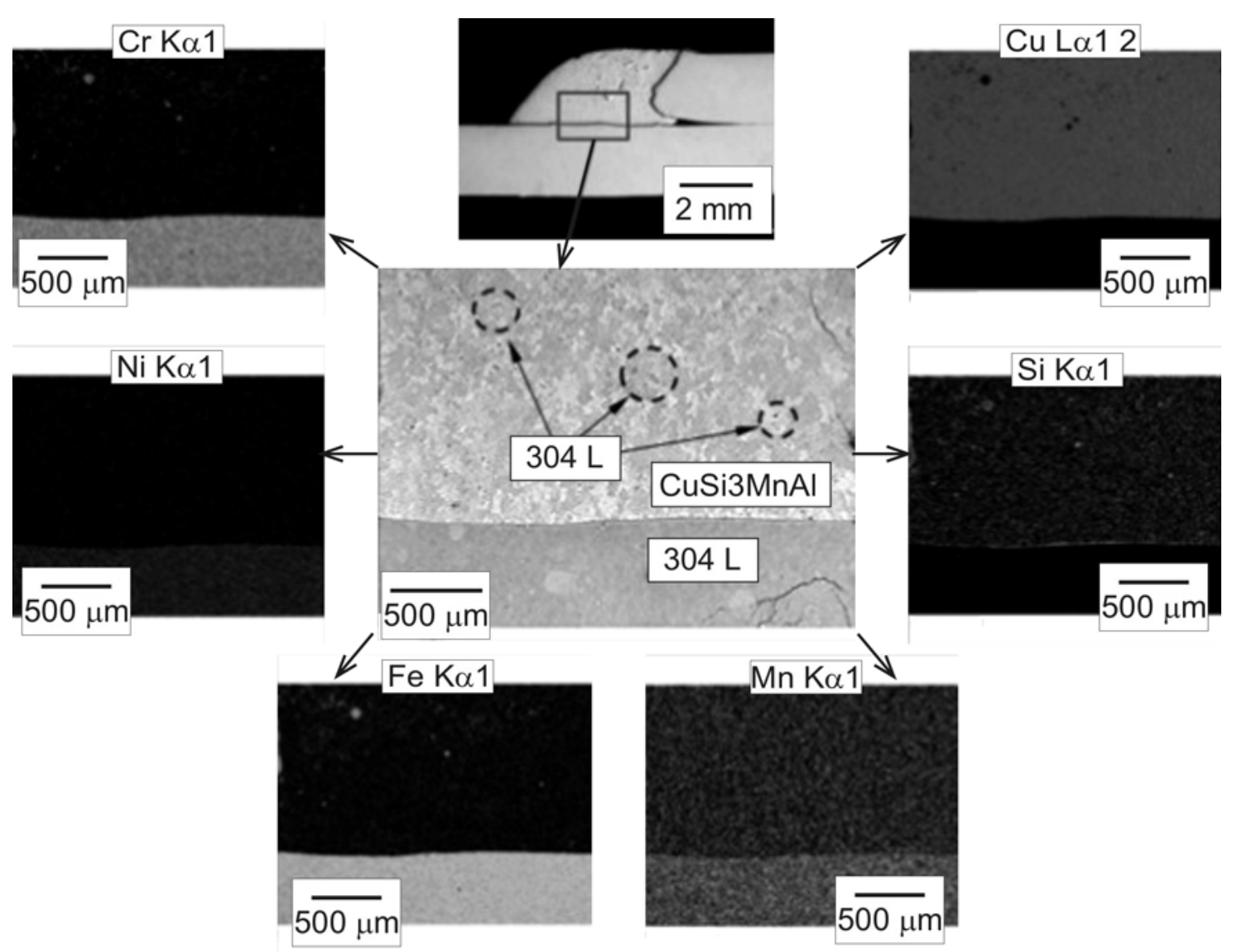

Fig. 6. EDX analysis showing element mapping focused on the presence of 304L elements in CuSi3MnAl braze metal. 
the joint strength, it was increased moderately to the value of $57.6 \%$. Results show that an optimum brazing speed with respect to achieving highest strength of joint at optimum GMA brazing parameters varies between $v=5.7$ to $6.7 \mathrm{~mm} \mathrm{~s}^{-1}$ and optimum width of bead between 5.7 to $6.3 \mathrm{~mm}$ (Fig. 4).

Furthermore, it can be concluded, that a direct factor determining the strength of the joint is the width of the brazed bead or the contact area between braze and base material. Width is expanding by increasing a filler material volume, but at lower brazing speeds. In the case of each tensile testing specimen, a failure was located in the braze contact area. The difference was found out in the location of the fracture. While the sample no. 1, Fig. 3a $(v=$ $9.7 \mathrm{~mm} \mathrm{~s}^{-1}$ ) shows the fracture exerted by the normal force (fracture is located perpendicularly to exerted force), sample no. $3\left(v=6.7 \mathrm{~mm} \mathrm{~s}^{-1}\right)$ and sample no. 4 $\left(v=5.7 \mathrm{~mm} \mathrm{~s}^{-1}\right)$, Figs. 3b,c, show the fracture exerted by the shearing tension. Consequently, the strength of the joint having lower width of a brazed bead depends on the strength of a braze itself, while the strength of a sample having higher width of bead depends on the strength of a braze-base material interface.

\subsection{Structural analysis of overlapped joints}

For the purpose of structural analysis, overlapped joints were cross sectioned (Table 5).

Joints did not exhibit any porosity, cavities or cracking defects. Melting of a base material can be observed on each of the overlapped joint samples. Melting occurred mostly on the upper edge of the plate, which is a critical location of the joint in the terms of low distance from an arc plasma channel and heat flow into a base material. The level of melting is in relation to the level of heat input to the brazed joint. Melting of the bottom plate of an overlapped joint was observed in minimum level.

Particles of a base material also occurred in the structure of a braze metal. In the braze matrix formed of the $\mathrm{Cu}$-based solid solution, various dimension particles were observed, which are incoherent with a braze matrix (Fig. 5).

Element mapping as a result of EDX analysis (Fig. 6) is documenting the composition of the base

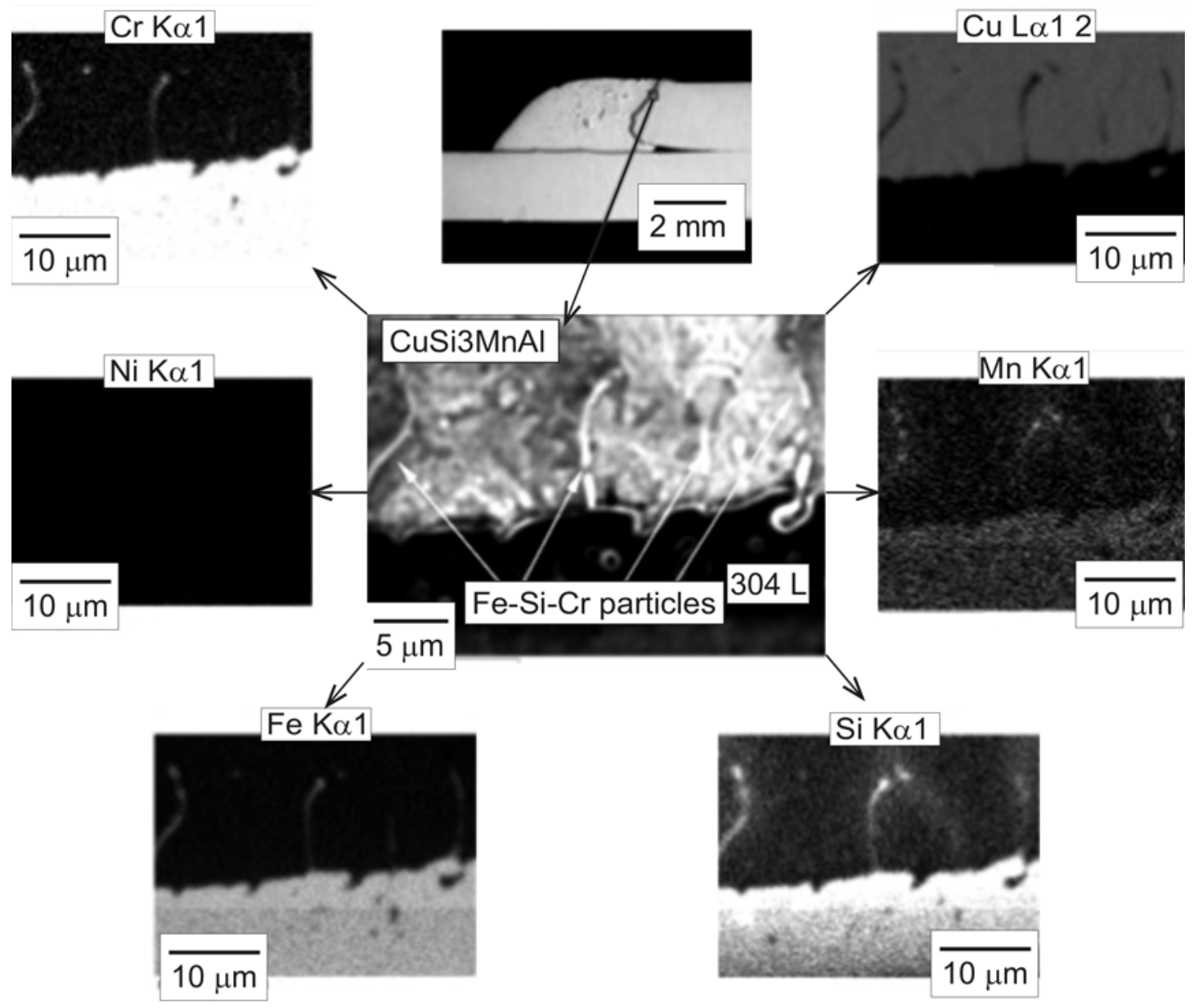

Fig. 7. EDX analysis documenting map of chemical composition focused on intermetallic fibre-weave shaped particles growing into braze metal CuSi3MnAl. 
material, and filler material alloying elements in the brazed joint. Distribution of $\mathrm{Fe}, \mathrm{Cr}$, and $\mathrm{Si}$ in the braze metal indicates the basic chemical composition of incoherent globular particles presented. Distribution of the rest of alloying elements $\mathrm{Mn}, \mathrm{Ni}$ and $\mathrm{Cu}$ in braze matrix is uniform.

Two identified types of incoherent particles are characterized by the difference in the shape and size. While high-sized coagulating particles are reaching the size of $100 \mu \mathrm{m}$, small-sized particles of non-uniform shape have the size up to $10 \mu \mathrm{m}$. It is assumed that globular particles have been formed by melting and migrating of a certain volume of base material into braze metal and that these particles are formed by the solid solution of $\mathrm{Cr}$ and $\mathrm{Si}$ in Fe. The level of coagulation depends on the thermal impact on the braze metal.

Furthermore, we assume that the formation mechanism of small sized incoherent particles in the shape of flowers/stars is similar as described by Yu et al. [16]. The formation, shape and distribution of particles is a result of $\mathrm{Fe}$ and $\mathrm{Cr}$ diffusion from the side of a base material into braze metal and diffusion of Si from the side of a braze metal into base material (Figs. 7, 8).

In the first stage of formation, fibrous-weave shaped particles are growing beginning on the peaks of weaved diffusion zone (Fig. 7). These particles are consequently fragmented by the effect of liquid metal turbulence into the short particles, which grow into the shape of flowers and stars (Fig. 8).

In the next step, diffusion layers have been analysed in the interface of a braze metal base material. The structure of diffusion layer depends on the level of base material melting (Fig. 9).

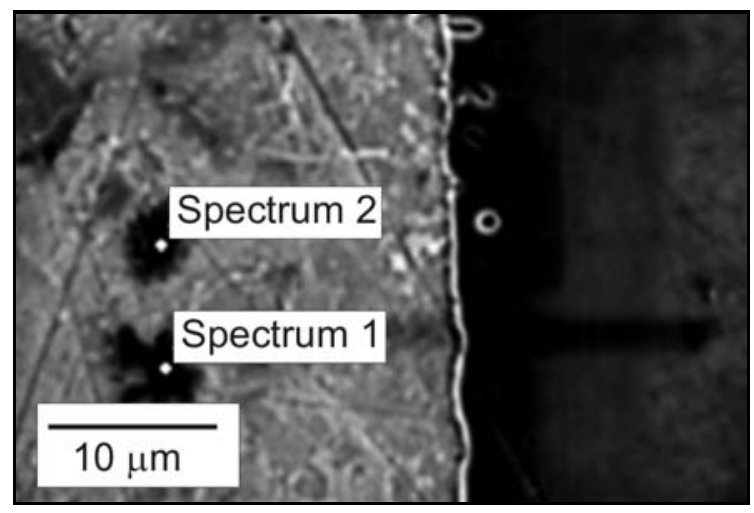

Fig. 8. Spot EDX analysis of star shaped intermetallic phases contained in the braze metal CuSi3MnAl.

Figure 9a documents a diffusion interface layer between a base material and braze metal in the nonmelted base material area. The thickness of this interface layer has been measured having not more than $10 \mu \mathrm{m}$. On Fig. 9b, there is a structure of interface layer in the area of a melted base material. In this case, the structure was affected in the thickness of $40 \mu \mathrm{m}$.

Taking the results of tension testing into account, melting of a base material during the brazing process does not affect mechanical properties of brazed joint, tested by the static tensile test. An overlapped joint performed in the scope of optimized brazing parameters at higher heat input (Fig. 3) showed the failure in the bottom part of a contact area, which is an area with minimum level of melting. In terms of the strength of the joint, an important role play: the width

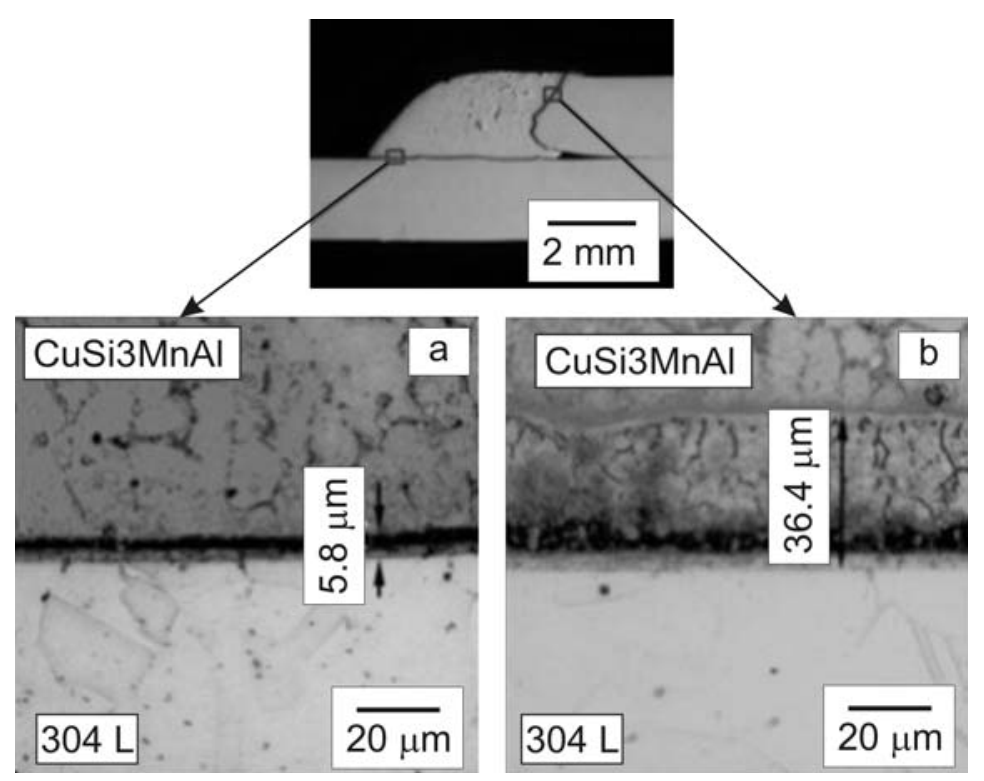

Fig. 9. Melted a) and non-melted b) interface layer between base material 304L and braze CuSi3MnAl. 

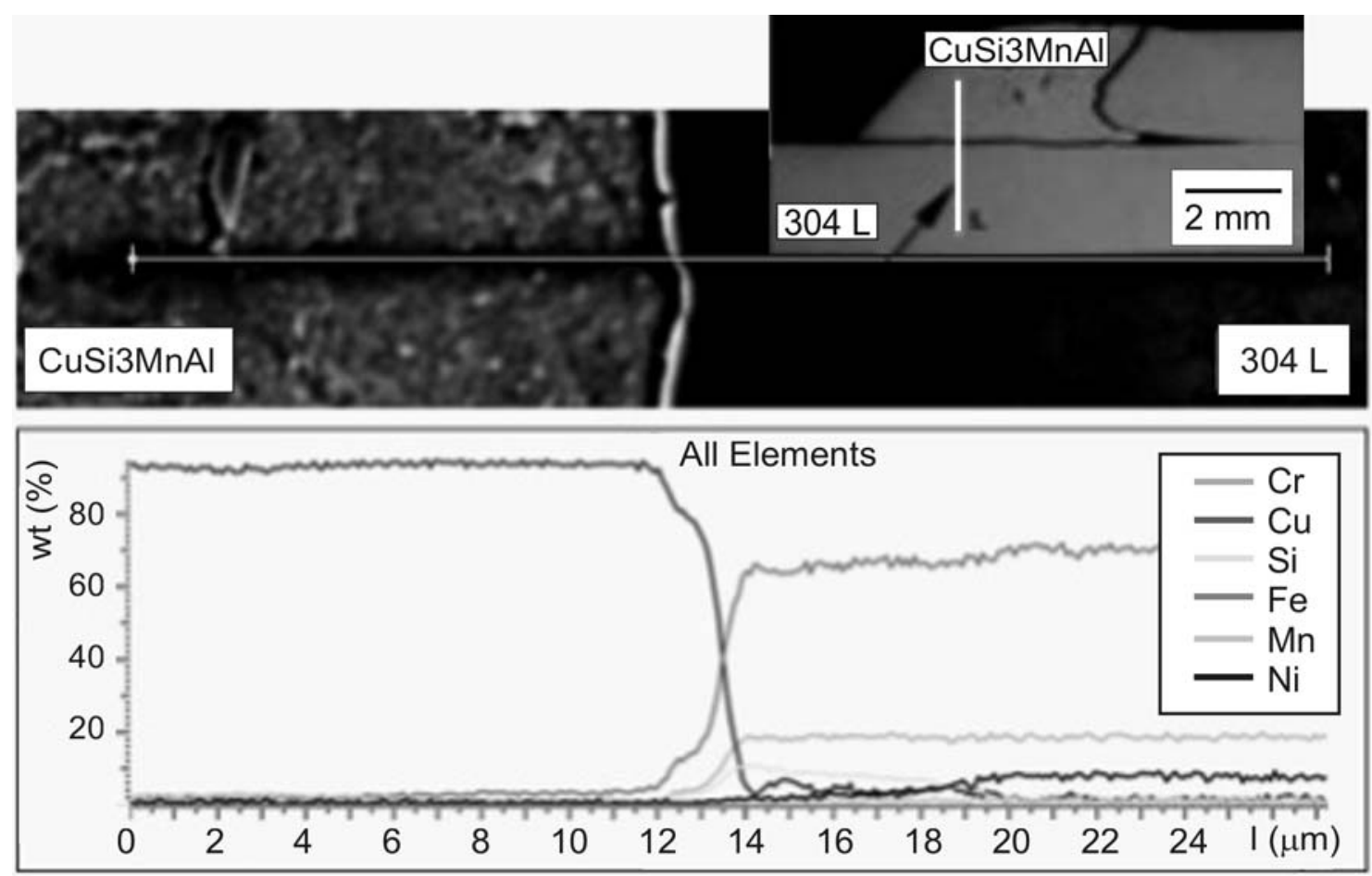

Fig. 10. EDX concentration profile of braze metal base material interface in the non-melted area.
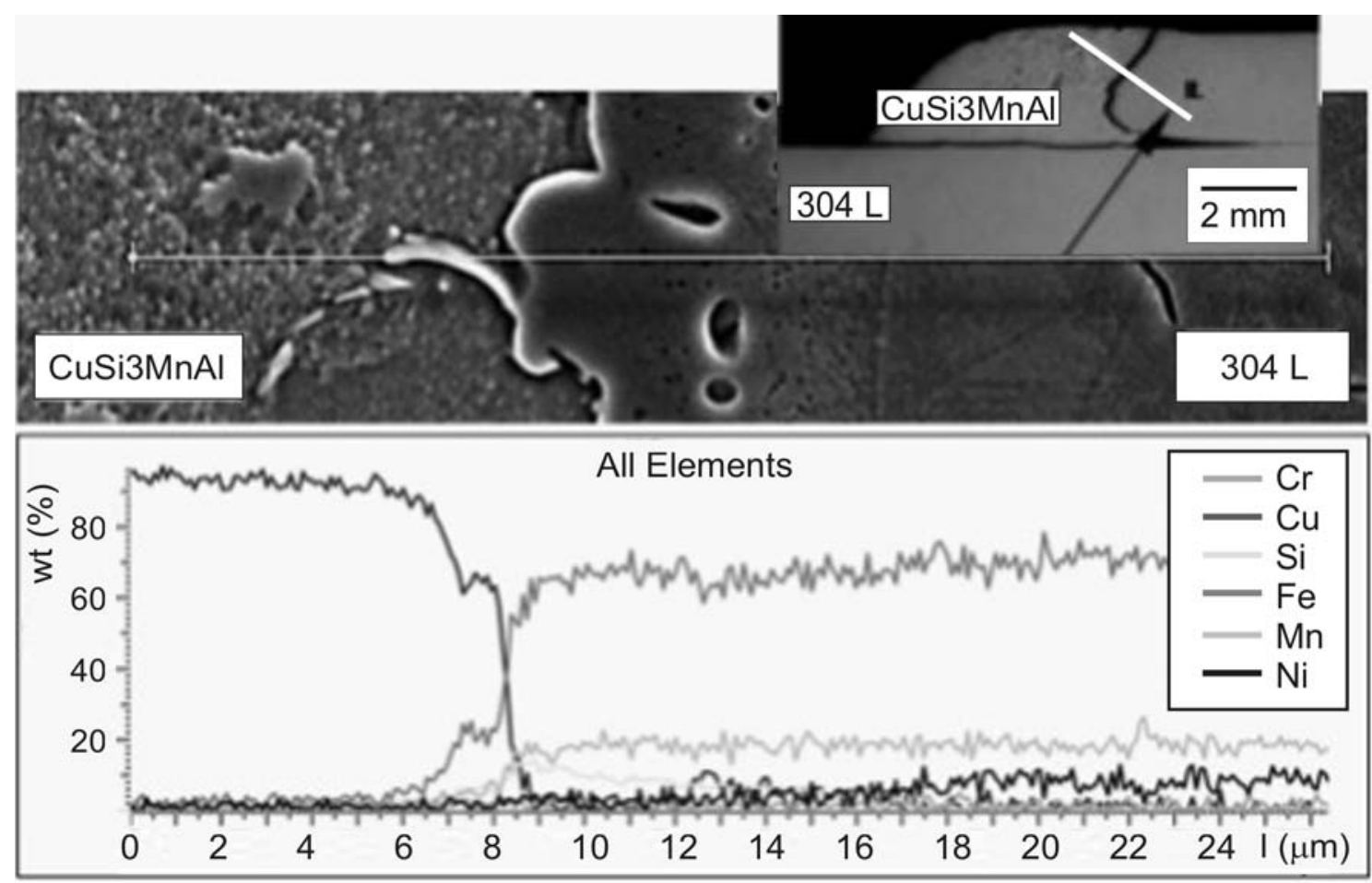

Fig. 11. EDX concentration profile of braze metal base material interface in the melted area.

of the contact area between a braze metal and base material (Fig. 4), and the structure of a diffusion interface layer braze metal-base material.

Linear EDX analysis of chemical elements distribution across an interface was performed for more de- tailed analysis of diffusion interface layer. Mass determination of presented elements ( $\mathrm{Cr}, \mathrm{Ni}, \mathrm{Fe}, \mathrm{Cu}, \mathrm{Si}$, $\mathrm{Mn}$ ) was examined in selected areas perpendicular to the interface of braze metal-base material (Figs. 10, 11). An elements progression profile in selected dif- 


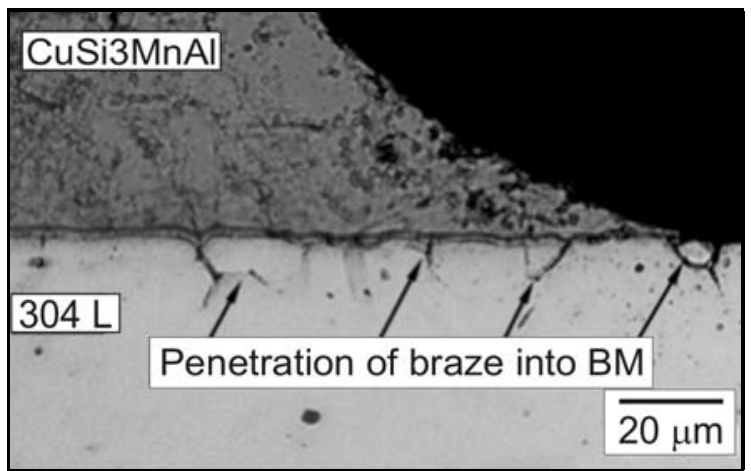

Fig. 12. Penetration of braze metal into 304L base material.

fusion area I (on the bottom part of a joint without melting) is given in Fig. 10.

Intensive diffusion of $\mathrm{Si}$ was observed from the side of the base material. In the distance of $7 \mu \mathrm{m}$ from the sharp interface of a braze metal-base material, maximum Si content $(11 \%)$ was measured. The high content of Si gives an assumption that the intermetallic phase $\mathrm{Fe}_{2} \mathrm{Si}$ can be formed, based on the mechanism, which is described in the work [16]. Moreover, it is known that an elevated content of $\mathrm{Si}$ in the combination with $\mathrm{Mn}$ and $\mathrm{C}$ will, inter alia, also affect the braze penetration into austenitic base material grain boundaries (erosion) [17]. This fact is confirmed not only by the high presence of $\mathrm{Cu}$ in the diffusion zone of a base material (Fig. 10), but is also based on the detailed analysis of an interface structure in the selected area (Fig. 12). Penetration of braze into a base material was observed when using a higher heat input and up to the thickness of $50 \mu \mathrm{m}$.

Dissolvability of alloyed steels in the liquid $\mathrm{Cu}$ based braze is much higher than dissolvability of carbon steels. In the interface zone containing a melted base material, there was an elevated content of $\mathrm{Cr}$ to $24 \%$ observed (Fig. 11). The rest amount of Fe in the braze metal (as a result of dissolving base material) precipitated in the form of ferritic crystals close to the contact area of a braze metal-base material.

\section{Conclusions}

The purpose of submitted paper was to analyse the production process of GMA brazed joints of an austenitic high alloyed steel using a solid and flux-cored wire. In order to meet the purpose of analysis, ASTM SA340 TP 304L steel sample plates of thickness $2.0 \mathrm{~mm}$, filler material CuSi3MnAl (flux-cored wire) and filler material $\mathrm{CuSi} 3$ (solid wire) were used for the production of sample built-up layers. Sample built-up layers were performed to optimize GMA brazing process parameters. Consequently, in the scope of optimized brazing process parameters, overlapped joints were produced, and furthermore, subjected to the evaluation of mechanical properties obtained by the tensile testing and also to the structure analysis of brazed joints. Based on the results obtained, following findings can be concluded:

- At applying CuSi3MnAl braze in the form of flux-cored wire, sample built-up layers exhibit a uniform shape, absence of spatter and no surface defects even at the higher brazing speed used. Surface defects and spatter were also indicated in the case of $\mathrm{CuSi} 3$ wire, however, the width of the brazed bead was evaluated at higher brazing speeds as non-uniform.

- When using CuSi3 braze in the form of solid wire, each of the built-up layer cross section (built-up layer performed at various heat input values) showed a melted base material and unsymmetrical shape of the built-up layer bead with big differences in wetting angle $\left(\alpha=48^{\circ}\right.$ to $\left.84^{\circ}\right)$. On the other hand, when using CuSi3MnAl braze, melting of base material did not take place even at maximum heat input applied $\left(Q=207.5 \times 10^{-3} \mathrm{~kJ} \mathrm{~mm}^{-1}\right)$. Built-up layer samples in cross-sections were evaluated as symmetrical in the shape of the bead and having an acceptable wetting angle measured in the range $\alpha=36^{\circ}$ to $45^{\circ}$.

- Overlapped joints performed by GMAB process using flux-cored wire CuSi3MnAl in the scope of optimized parameters did not exhibit any surface or volumetric defects. The width of brazed bead was proportional to the heat input and was varying from 4.6 to $6.3 \mathrm{~mm}$.

- Tensile testing of these joints resulted in the failure located in the braze. To evaluate the strength of joint, methodology based on comparing the maximum force $F_{\max }$ obtained from a tensile testing of joints to $F_{\max }$ obtained from a base material was applied. By comparison, it was found out that the strength of GMA brazed joints depended on the width of the braze contact area and was lower than the strength of a base material - in our case, the strength of joints (depending on the width of a brazed bead) varied in the range 26.9 to $57.9 \%$ of a base material strength.

- Multi-phase braze metal structure is influenced by the level of melting and dissolving of a base material. It consists of a $\mathrm{Cu}$-based matrix and incoherent particles of variable dimensions and high content of $\mathrm{Fe}$ and $\mathrm{Cr}$. Globular particles having a size up to $100 \mu \mathrm{m}$ are the result of melting of certain larger volume of a base material into the braze, while small sized particles in the shape of flower or star (up to $10 \mu \mathrm{m}$ size) enter the interface braze metalbase material, which is enhanced with $\mathrm{Fe}$ and $\mathrm{Cr}$ (by the diffusion from a base material), and $\mathrm{Si}$ (from the braze). We assume that the mechanism of incoherent star particles formation is the same as described by Yu et al. [16].

- The width of the interface braze metal-base ma- 
terial depends on the level of base material melting and varies between 10 to $40 \mu \mathrm{m}$. An elevated content of $\mathrm{Fe}$ and $\mathrm{Si}$ gives the assumption of the formation of intermetallic phase $\mathrm{Fe}_{2} \mathrm{Si}$. Moreover, the content of $\mathrm{Si}$ in the combination of $\mathrm{Mn}$ and $\mathrm{C}$ has an influence on the penetration of a braze to the grain boundaries of an austenitic base material, what has been observed mostly in the interface diffusion area of a base material located at the end of the braze to a base material transition.

\section{Acknowledgement}

The results presented in the paper were achieved as a part of VEGA grant No. 1/0234/11.

\section{References}

[1] Dilthey, U., Höcker, F.: In: Proceedings of $57^{\text {th }}$ International Conference of IIW. Osaka, Japan, 2004, p. 31. ISBN4-90611046-6

[2] Hackl, H.: Welding Review International. Redhill, UK, DMG World Media Ltd. 1996.

[3] Sejč, P., Bielak, R., Švec, P., Roško, M.: Kovove Mater., 44, 2006, p. 225.

[4] Viňáš, J., Kaščák, L., Draganovská, D.: Acta Metallurgica Slovaca, 18, 2012, p. 162.
[5] Mičian, M., Meško, J., Banaš, F.: In: Nekonvenčné technologie 2008. Special Processes 2008. Eds.: Englárt, A., Moravec, J. Žilina, EDIS 2008, p. 234. ISBN 978-80-8070-859-7

[6] Sejč, P., Belanová, J., Kubíček, R.: Kovove Mater., 49, 2011, p. 437.

[7] Catalogue of Filler Materials. ESAB Slovakia 2007. (in Slovak).

[8] Chovet, C., Guiheaux, S.: La Metallurgia Italiana, 78, 2006, p. 47.

[9] Herman, P.: Zváranie - Svařování, 9-10, 2002, p. 213.

[10] ASM Handbook: Welding, Brazing and Soldering. Vol. 6. Materials Park, ASM International 1993.

[11] Schwartz, M.: Brazing. Materials Park, ASM International 1987.

[12] The Inspection Certificate 2.1. Additional Material ASTM SA240 TP 304L. (in Slovak).

[13] The Inspection Certificate 3.1. Additional Material ESAB OK AUTROD 19.30. (in Slovak).

[14] The Inspection Certificate 3.1. Additional Material MECUFIL 903Al. (in Slovak).

[15] STN EN 1011-1. Welding. Recommendations for Welding of Metallic Materials. Part 1: General Guidance for Arc Welding. (in Slovak).

[16] Yu, Z., Li, R., Qi, K.: Transactions Nonferrous Metals Society of China, 16, 2006, p. 1391. doi:10.1016/S1003-6326(07)60026-0

[17] Lippold, J. C., Kotecki, D. J.: Welding Metallurgy and Weldability of Stainless Steels. New Jersey, Wiley Interscience 2005 . 